\title{
Tecnologia Móvel: Relato de Experiência na Formação de Gestores
}

\author{
Maria Bernadete O. de Melo ${ }^{1}$, Mixilene S. S. Lima ${ }^{2}$, Karla Angélica S. Nascimento ${ }^{2}$ \\ e José Aires de Castro Filho ${ }^{1}$ \\ ${ }^{1}$ Instituto Universidade Virtual - Universidade Federal do Ceará (UFC) \\ Fortaleza - Ceará - CE - Brasil \\ ${ }^{2}$ Faculdade de Educação - Universidade Federal do Ceará (UFC) \\ \{bernaoria,mixilene, Karla, aires \} dvirtual.ufc.br
}

\begin{abstract}
This article presents the experience of managers in the training course for the use of mobile technologies, developed in blended mode. The article discusses the development of course part of a coordinated action of the practice of school manager entered public schools in a municipal school for the continued use of the LIE Mobile. From this action we expect the manager to continually seek new knowledge and training required for this insertion. As the core methodology, we mention the application of survey, registration of project design for implementation of mobile technology in the school and statements issued by management.
\end{abstract}

Resumo. Este artigo apresenta a experiência de gestores no curso de formação para o uso das tecnologias móveis, desenvolvido na modalidade semipresencial. $O$ artigo aborda o desenvolvimento do curso que parte de uma ação articulada da prática do gestor escolar inserido em escolas publicas de uma rede municipal de ensino para o uso contínuo do LIE Móvel. Partindo desta ação esperamos que o gestor possa buscar continuamente a capacitação e novos conhecimentos necessários para esta inserção. No que cerne a metodologia, citamos a aplicação de sondagem, registro da elaboração do projeto para implantação da tecnologia móvel na escola e depoimentos emitidos pelos gestores.

\section{Introdução}

As transformações sociais e educacionais durante estes últimos anos no Brasil são reflexos da aceleração das mudanças que vêm ocorrendo, sobretudo a partir da década de 90 em que a tecnologia passou a ser vista como componente importante do processo educacional como um todo.

Para os governos e agentes sociais, as políticas de qualificação dos recursos humanos merecem o máximo de interesse e prioridade, pois os processos formativos devem caracterizar continuidade, atualização e renovação em seus conteúdos. E isso deve atingir o maior número possível de profissionais.

Neste sentido, a incorporação das Tecnologias de Informação e Comunicação (TIC) na escola contribui para expandir o acesso à informação atualizada e, principalmente, para promover a criação de comunidades colaborativas de aprendizagem que privilegiam a construção do conhecimento, a comunicação, a 
formação continuada e a gestão articulada entre as áreas administrativa e pedagógica da escola. Por isso, a formação continuada de gestores para a inserção das tecnologias móveis nas escolas públicas não pode ser diferente, principalmente porque esses recursos estão, cada vez mais, sendo inseridos no cotidiano escolar.

A partir desses pressupostos o Projeto Um Computador por Aluno (UCA), com o intuito de promover a inclusão digital nas escolas das redes públicas mediante a aquisição de computadores portáteis, preocupa-se em capacitar professores e gestores para a utilização das tecnologias móveis que auxiliem os processos de ensino e de aprendizagem dentro e fora da escola [Brasil 2009].

Com o propósito de conhecer o perfil e o papel do gestor frente às tecnologias móveis e sua contribuição para que estes recursos sejam incorporados à comunidade escolar, descrevemos o processo de formação de gestores desenvolvido pelo Instituto Universidade Virtual conjuntamente com o Centro de Referência do Professor (CRP) órgão vinculado a Prefeitura Municipal de Fortaleza.

Iniciamos com uma breve revisão sobre a formação continuada de gestores e as tecnologias móveis quanto à qualificação e formação de 39 (trinta e nove) gestores de escolas municipais de Fortaleza. Em seguida, apresentamos os pressupostos metodológicos para a organização do nosso estudo. $\mathrm{Na}$ sequência, expomos os resultados, fruto dos dados coletados nos instrumentos de sondagem e análise dos projetos dos cursistas e, por último, as considerações finais.

\section{Formação continuada de gestores e as tecnologias móveis}

A gestão escolar é repleta de ações e tarefas variadas que fogem a uma ação mais primordial, a pedagógica. Uma pesquisa feita pela Fundação Victor Civita (FVC), em parceria com o Instituto Brasileiro de Opinião Pública e Estatística (IBOPE), constatou que o dia a dia do gestor é mais marcado por tarefas administrativas do que dirigir a relação entre ensino e aprendizagem, orientar para o saber e gerenciar o conhecimento [Fundação Victor Civita 2010].

Estudos recentes têm comprovado que o crescimento econômico e a competitividade das economias mais avançadas dependem primordialmente da capacidade para inovar os produtos e os processos, e que esta capacidade está baseada num elevado nível de conhecimentos profissionais dos trabalhadores [Fundação Victor Civita 2010]. Em consonância com este pressuposto temos a figura do gestor escolar que também precisa rever e redirigir os processos que envolvem a sua prática na educação.

Para que se favoreça o desenvolvimento das condições ideais na utilização e aplicação das tecnologias digitais e móveis pela gestão, é necessário planejar, de forma articulada, o processo de ensino e de aprendizagem [Almeida e Prado 2009].

A gestão escolar consiste num espaço de mobilização da competência e do envolvimento das pessoas coletivamente para que, por sua participação ativa e competente, promovam a realização dos objetivos educacionais. No entanto, para que isso aconteça é preciso uma transformação na escola, envolvendo toda a comunidade escolar no trabalho realizado em seu interior. 
De acordo com Almeida e Valente [2011, p.10], o envolvimento dos gestores escolares na articulação dos diferentes segmentos da comunidade escolar, na liderança do processo de inserção das TIC na escola em seus âmbitos administrativo e pedagógico e, ainda, na criação de condições para a formação continuada e em serviço dos seus profissionais, pode contribuir e significativamente para os processos de transformação da escola em um espaço articulador e produtor de conhecimentos compartilhados.

Neste sentido, é necessário que haja empenho e envolvimento do gestor escolar no processo de formação continuada para o uso das tecnologias móveis na educação, pois, segundo Moran [2012, p. 01], as tecnologias móveis trazem enormes desafios:

podemos aprender em qualquer lugar, a qualquer hora e de muitas formas diferentes. Podemos aprender sozinhos e em grupo, estando juntos fisicamente ou conectados. Na medida que entram na sala de aula o seu uso não pode ser só complementar. Podemos repensar a forma de ensinar e de aprender, colocando o professor como mediador, como organizador de processos mais abertos e colaborativos.

Esses desafios têm sido representados nas formações continuadas fortemente incentivada pelo Ministério da Educação (MEC), através de programas de capacitação que visam à preparação de professores e gestores para o uso das tecnologias digitais. Dentre eles podemos destacar: o ProInfo criado em 1997, vigente até hoje. Este é considerado uma das primeiras propostas do Governo Federal mais importante para informatização das escolas públicas no país, pois integra vários projetos. Segundo Vidal et al (2002) "a diretriz fundamental do Proinfo é a mobilização de esforços para a introdução da tecnologia da informática no processo de ensino- aprendizagem nas escolas públicas de Ensino Fundamental e Médio". O Mídias na Educação que tem como objetivo a formação continuada de professores para o uso pedagógico das tecnologias de informação e comunicação. O Projeto Um Computador por Aluno tem como pressupostos a interação e a reflexão, unindo a prática pedagógica, o currículo, as tecnologias e as teorias educacionais que permitem entender e modificar as práticas, a fim de aprimorar a aprendizagem do aluno.

No Projeto UCA, a formação engloba três dimensões: a tecnológica, que trata sobre a apropriação dos recursos tecnológicos existentes nos laptops educacionais; a pedagógica, que trabalha com o processo de ensinar e aprender a partir da utilização do laptop envolvendo a comunidade escolar; e a teórica, que permite compreender criticamente e reconstruir as práticas pedagógicas e de gestão da sala de aula e da escola [Almeida e Prado 2009].

Através dos encontros de formação, o projeto UCA, está permitindo que o professor compreenda a importância da construção de redes de relações docentes e da aprendizagem colaborativa, a fim de promover a construção de conhecimentos pedagógicos compartilhados a partir da utilização do laptop com seus alunos. Segundo Nascimento [2011, p.09] "os professores e gestores da escola pouco a pouco estão se conscientizando da necessidade de conhecer melhor o Projeto UCA e de inserir, com maturidade, os recursos tecnológicos digitais em suas práticas pedagógicas".

Estudos de Prado, Borges e França [2011, p. 61], indicam que "fazer uso integrado dos recursos computacionais aos conteúdos curriculares não é algo simples de acontecer, pois requer um processo de reconstrução de um conhecimento que vai além 
da apropriação dos recursos computacionais". Este conhecimento deve perpassar a inclusão digital de professores, alunos e gestores.

Por isso, o processo de formação é crucial, e deve acontecer de modo amplo, em especial, no uso das tecnologias digitais e móveis, visto que a demanda atual dos programas de inclusão tecnológica nas escolas estejam preparados para gerir a dinâmica da escola. A inclusão digital deve contemplar "questões relacionadas à prática escolar e com as políticas curriculares" [Almeida e Prado 2009, p.02].

Para tanto, foi criado um projeto que oferta cursos de Gestão Escolar e Tecnologias, desenvolvido por alguns estados e universidades brasileiras, dentre os quais citamos o Instituto Universidade Virtual da Universidade Federal do Ceará, que adaptou o modelo de formação para atender as questões regionais.

Desde 2009, por meio do convênio com a Prefeitura Municipal de Fortaleza e a Secretaria Municipal de Educação, o Instituto Universidade Virtual vem se preocupando com a formação dos gestores das escolas municipais, oferecendo cursos voltados ao uso das tecnologias digitais. Estes cursos propõem uma discussão sobre a articulação entre a prática do gestor escolar, as teorias educacionais e o uso das Tecnologias de Informação e Comunicação (TIC), tendo como ambiente virtual de aprendizagem SÓCRATES, desenvolvido pelo Instituto Universidade Virtual.

Em 2012 o curso "Gestão das Tecnologias da Informação e Comunicação na Escola" recebeu uma nova proposta de incluir digitalmente os gestores e de elaborar um projeto para a incorporação das tecnologias móveis no cotidiano escolar, denominado de Laboratório de Informática Educativa Móvel (LIE Móvel).

A seguir apresentaremos os procedimentos metodológicos da pesquisa, a fim de esclarecer as etapas e propostas do curso em questão.

\section{Metodologia}

A pesquisa tem abordagem qualitativa de caráter descritivo, que segundo Gil (2002), delineia as características de determinada população, fenômeno ou o estabelecimento de relações entre variáveis. Implica a utilização de questionário e observação ordenada e padronizada. Para esta ação aplicamos um instrumento de acompanhamento, a fim de orientarmos às questões pertinentes a pesquisa.

Neste estudo, dentre suas possibilidades de intervenção, foi aplicado um questionário para 39 (trinta e nove) gestores, com o objetivo de investigar o perfil e o papel do gestor frente às tecnologias móveis. Além disso, no final do curso, foram analisadas propostas dos projetos, a fim de saber quais as contribuições dos gestores para incorporar as tecnologias móveis à comunidade escolar.

Segundo Gil (2002), o questionário possibilita ao pesquisador a obtenção dos dados em profundidade. Assim, esse instrumento foi elaborado pela equipe de formação do Instituto Universidade Virtual. Com a aplicação deste, coletamos os dados sobre perfil do gestor em relação ao uso das tecnologias digitais na educação. Além disso, no início do curso, identificamos as percepções, aprendizagens, apropriação tecnológica, bem como o entendimento dos gestores sobre a chegada das tecnologias móveis na escola. 
Com base no objetivo primordial do curso, que foi a elaboração de um projeto e plano de ação de inclusão dos LIE Móveis na escola, conseguimos estabelecer um breve comparativo do perfil inicial dos gestores e suas apropriações tecnológicas a serviço da educação observadas no final do curso. A preocupação de capacitar os gestores se deve ao fato de que $90 \%$ dos gestores participantes do curso já tinham recebido os LIE Móveis e os outros $10 \%$ estavam em vias de receber. Portanto, existia naquele momento a necessidade de uma apropriação mínima necessária para que esta ação pudesse acontecer da forma mais eficiente.

Para iniciar o curso foi possível refletir sobre o significado da função do gestor frente às tecnologias digitais e móveis e perceber qual a relação do gestor com estas novas exigências. No decorrer do curso foi aplicada sondagem e aconteceram reflexões dialogadas onde os gestores puderam avaliar sua prática profissional.

Dessa forma, algumas questões foram levantadas: como as tecnologias estão inseridas no cotidiano do gestor? Quais as expectativas da inserção do LIE móvel? De que forma o gestor está inserido no Projeto de Tecnologia Móvel da escola? Para Moran [2012, p02] "as tecnologias móveis desafiam as instituições a sair do ensino tradicional em que os professores são o centro, para uma aprendizagem mais participativa e integrada, com momentos presenciais e outros a distância, mantendo vínculos pessoais e afetivos, estando juntos virtualmente".

Os propósitos desse curso também reforçam as necessidades de contextualizar os temas estudados e as estratégias desenvolvidas como indicadores de quais tecnologias devem ser integradas ou se é apropriado utilizar tecnologias em determinada situação educacional. Para Alonso e Almeida [2004, p.5]

é importante romper com as concepções que centram o trabalho dos dirigentes escolares no cumprimento de tarefas rotineiras, de caráter burocrático, fortemente associado ao trabalho administrativo, sem conexão com as atividades de natureza pedagógica, cuja atribuição e responsabilidade cabem ao corpo docente e técnico-pedagógico.

Ainda segundo os autores, é imprescindível romper as barreiras do medo do desconhecido e tomar consciência dessa limitação para compreender os pressupostos da tecnologia móvel na escola "de forma a permitir uma reinterpretação dessa função e um novo encaminhamento do próprio trabalho em consonância com as necessidades e diretrizes educacionais da sociedade contemporânea" [Alonso e Almeida 2004, p.5].

\section{Resultados}

A análise dos dados foi feita com caráter qualitativo. É através deste tipo de análise que podemos alcançar um nível desejável de compreensão das percepções, crenças e relações pessoais dos participantes, considerando o contexto da pesquisa.

\subsection{O curso de formação de gestores}

O Curso "Gestão das Tecnologias da Informação e Comunicação na Escola" propôs uma discussão sobre a articulação entre a prática do gestor escolar, as teorias educacionais e o uso das TIC na gestão escolar. O curso partiu de uma ação organizada pela equipe gestora, com o uso das tecnologias e teve como produto final a elaboração de um projeto para a incorporação das tecnologias móveis no cotidiano escolar. 
O curso ministrado na modalidade semipresencial teve duração de sessenta horas, divididas em: dez horas de aulas presenciais e quarenta horas de atividades à distância. O curso contou com a participação de 39 (trinta e nove) gestores e foi realizado no Centro de Referência do Professor (CRP), vinculado a SME. O CRP é um espaço onde os professores e gestores do sistema municipal de Fortaleza têm acesso aos cursos de formação continuada para o uso das tecnologias digitais na escola.

As atividades à distância foram realizadas no SÓCRATES. Os gestores participavam das leituras especializadas, discussão em fóruns, elaboração de textos anexados aos portfólios de grupo e individuais e produção de slides. Estas atividades complementares foram elaboradas visando à criação de uma cultura de estudo pelo gestor, uso da internet fora do espaço da escola, formação à distância, interatividade com os participantes inseridos no ambiente virtual e o compartilhamento de informações pelos integrantes do curso.

No inicio do curso foi traçado perfil dos gestores por meio de instrumento de sondagem, dos 39 gestores que concluíram o curso, 35 responderam o instrumento de sondagem. Através deste instrumento foi possível obter a média de idade dos cursistas, entre 27 e 58 anos de idade, destes, 8 eram formados em Pedagogia, sendo que 7 possuíam pós graduação, não especificado, apenas 3 respondera possuir pós-graduação em gestão escolar.

No uso da Internet, 74\% afirmaram utilizar principalmente para acesso a e-mail. As redes sociais ficam e segundo lugar, 16 gestores responderam acessar com frequência, totalizando $52 \%$.
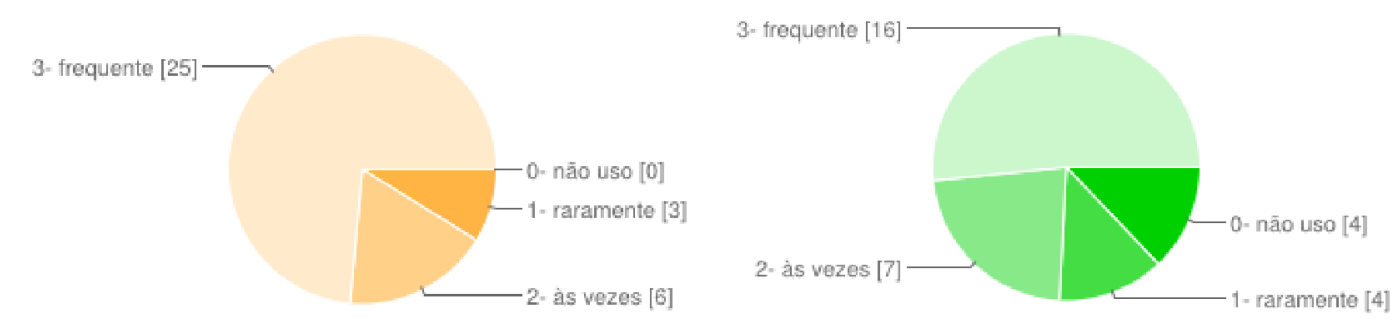

\section{Gráfico 1. Frequência de uso do e-mail Gráfico 2. Frequência de uso das redes sociais}

Ainda podemos observar que 59\% dos gestores usam a elaboração de relatórios e avaliações e $48 \%$ para planejamentos e planos de aula. Como podemos observar nos Gráficos 3 e 4.

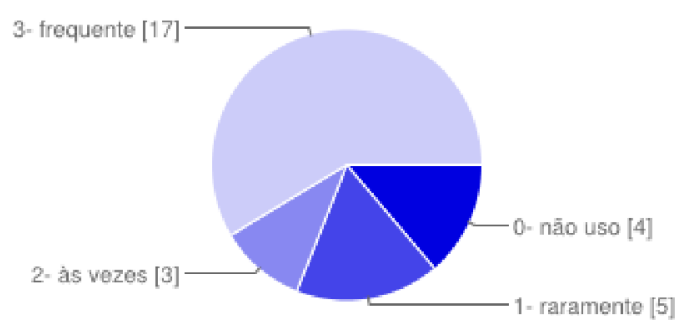

Gráfico 3. Frequência Planejamentos

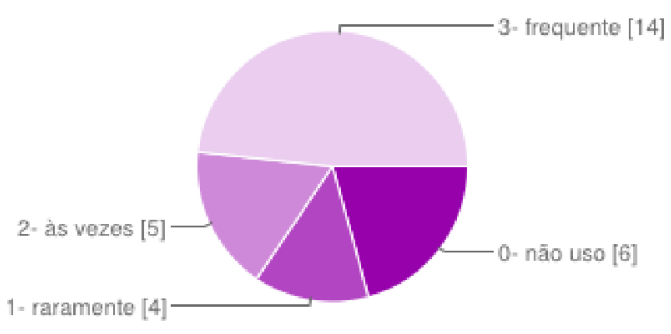

Gráfico 4. Frequência Planos de aula

Nas habilidades para o uso do computador, 53\% afirmam usar com frequência o editor de texto, $11 \%$ planilha eletrônica e $23 \%$ apresentação de slides, respectivamente observados nos Gráficos 5, 6 e 7. 


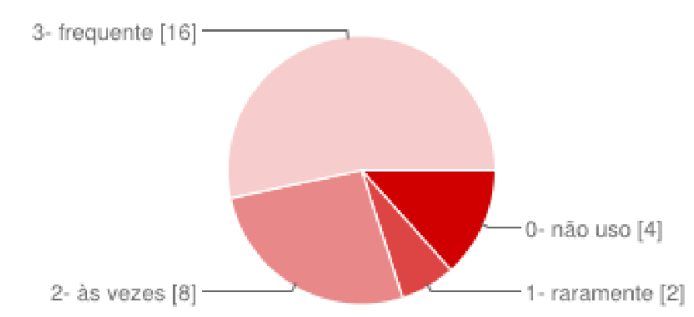

Gráfico 5. Frequência Editor de Texto

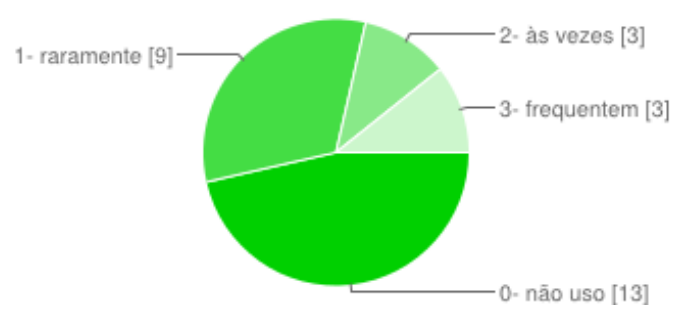

Gráfico 6. Frequência Planilha de cálculo

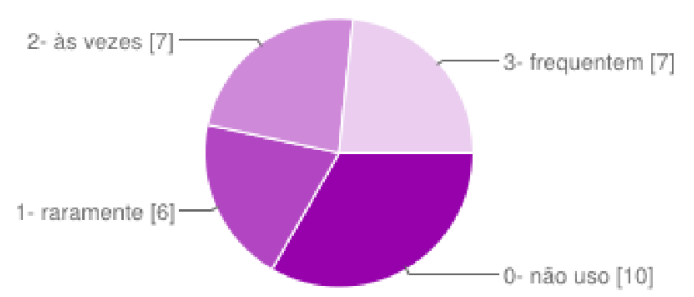

\section{Gráfico 7. Frequência Apresentação de Slides}

Em linhas gerais, podemos afirmar que o uso das TDIC para o modo básico pelos gestores é escasso. Conforme os gráficos, este uso se dá para acesso a e-mails e as redes sociais. Este fenômeno ocorre pela falta de uma apropriação mínima necessária para o uso destes recursos.

Ainda sobre a apropriação tecnológica, percebemos que ao término do curso os gestores se sentiram mais confiantes e conseguiram ultrapassar a barreira da resistência ao novo. Procuraram entender as ferramentas do sistema Linux Educacional, bem como os aplicativos de escritório: editor de texto, planilha eletrônica e apresentação de slides.

Ajudou-me a descobrir o novo (Linux) e tirar preconceito sobre o sistema. [Gestor1]

O curso foi de grande valia pra mim, porque além de me deixar mais informatizada, para trabalhar com o laboratório móvel, me ajudou também a socializar com o manejo digital através do computador. Agora me sinto segura e motivada a repassar para o colegiado de professores; bem como com a comunidade externa da escola. [Gestor3]

Percebemos que o educador não pode ficar a margem do mundo digital, a tecnologia está ao nosso redor e precisamos nos apropriar destas ferramentas educativas. [Gestor5]

O curso foi proveitoso porque me ofereceu a oportunidade de enfrentar meu receio em produzir textos no computador e trocar experiências com pessoas que compartilhavam os mesmos medos. [Gestor11]

Avalio o nosso curso, como sendo um momento ímpar para a nossa prática pedagógica. Aprendi pela necessidade e hoje me senti bem capacitada em manusear essa ferramenta, porém o LINUX é novo para mim, mas aos poucos venho fazendo progresso e devo isso as minhas formadoras. [Gestor12]

Ao observar o comportamento dos gestores em relação às aulas presenciais percebemos que durante o curso o nível de participação e integração aumentou, elevando também a autoestima, tanto nas discussões como nas produções das atividades.

Esse momento foi de suma importância para minha vida pessoal e profissional, nós gestores precisamos desses momentos de formação e que sejam contínuos, principalmente em quem nos leva a motivar nossa 
autoestima para que possamos inovar e inserir novos conhecimentos tecnológicos. [Gestor 8]

Encontramos duas facilitadoras muito capacitadas, seguras dos seus papeis que, de forma agradável, sempre nos orientavam e cobravam a realização das nossas tarefas. Incentivando-nos sempre, nos fizeram mais seguras e assim, foi possível quebrar o gelo e buscar segurança para o uso e manuseio das mídias digitais. [Gestor6]

Com base nos aspectos metodológicos do curso, os gestores reconheceram que os tópicos estudados foram bem elaborados e partiram das necessidades das escolas. Além disso, houve a real preocupação em abordar experiências inovadoras de utilização das tecnologias móveis que podem ser inseridas nos projetos pedagógicos das escolas, com a ajuda dos professores, alunos, pais e comunidade.

Enfim, excelente metodologia, material atual, ótimo ambiente, parcerias valiosas. Tudo isso muito nos incentivou a não parar por aqui. Devemos mais e mais buscar alargar nossos conhecimentos para que possamos dar o suporte necessário e esperado pelo coletivo de professores para a implantação do LIE Móvel e torá-lo um sucesso no cotidiano escolar. [Gestor6]

O curso foi esclarecedor, pois trouxe a tona questões relevantes no uso da tecnologia nas escolas. Nos fez refletir sobre as fragilidades que encontramos no ambiente de trabalho onde professores não possuem habilidade no uso do computador. [Gestor7]

O curso foi uma excelente oportunidade para as escolas, partiu de uma necessidade. [Gestor9]

O curso do laboratório móvel me proporcionou momentos de leitura, questionamentos e conhecimento de novas experiências. O tempo do curso foi bem aproveitado entre momentos diferentes proporcionando um ambiente de aprendizagem e ao mesmo tempo de companheirismo. As formadoras souberam conduzir muito bem o curso. [Gestor10]

Através dos depoimentos observamos uma evolução significativa denotada na fala do gestor cursista no que tange principalmente ao uso das tecnologias e na possibilidade de atuação desta aquisição na sua prática escolar. Fica visível que a participação no curso foi um marco forte para o desempenho do papel de gerir as ações cabíveis também desenhadas para a chegada do LIE móvel nas escolas em que estes estão inseridos.

\subsection{Projeto de tecnologia móvel na escola}

Para fechamento e avaliação do curso, a turma de gestores foi dividida em seis equipes para elaboração da atividade final que teve como objetivo elaborar um projeto de tecnologia móvel na escola, a partir das necessidades de cada escola.

Neste sentido, elaboramos um modelo de estrutura simplificada de projeto, no qual os gestores deveriam seguir. Os elementos contidos em cada projeto foram: título, objetivo geral, objetivos específicos, metodologia, subsídios e recursos para o projeto e avaliação. Veremos a seguir os aspectos em comuns apresentados pelas equipes de gestores.

Com base nos objetivos gerais, quatro equipes apresentaram que o projeto deve: promover inclusão digital, democratizar o acesso aos meios de comunicação moderna através do uso de um computador na escola, intensificar o uso das TIC na perspectiva da construção da aprendizagem significativa, estimular a autonomia dos alunos e 
professores, visando desenvolver competências e habilidades que auxiliem o processo de ensino e de aprendizagem. Duas equipes informaram que o objetivo principal está em inserir o LIE Móvel, através de ações coletivas, integrando a comunidade escolar.

Em relação aos procedimentos metodológicos para viabilização do projeto na escola, duas equipes informaram que pretendem investigar o nível de conhecimento dos professores sobre o uso das tecnologias na escola. Essa sondagem deverá ser socializada com a SME para elaboração de cursos de formação docente. Todas as equipes apresentaram a necessidade de elaborar um plano de ação com os professores para contemplar todos os passos de implementação do projeto na escola. Sobre a formação continuada, todas as equipes concordam que o projeto precisa capacitar os docentes e alunos-monitores para melhor desenvolvimento do projeto.

Percebemos que somente três equipes apresentaram subsídios e recursos para o projeto. Essas focaram nos elementos imprescindíveis para ter uma estrutura física e técnica bem organizada para viabilização do projeto, como: iluminação adequada, quadro branco com pincel, aparelhos para recarga dos laptops, acesso à Internet sem fio; sistema de rede local; um laptop para cada professor da escola e projetor multimídia. Além disso, as equipes reforçaram a necessidade da infraestrutura para uma reforma no LIE, inserindo ar condicionado, revisão na instalação elétrica e de grades de segurança na entrada das salas. Em relação aos recursos humanos, as três equipes apresentaram a necessidade de um profissional da área da educação com conhecimento na área de Informática Educativa que possa servir de apoio para os demais profissionais da escola, bem como fazer a entrega dos aparelhos por sala.

Desta forma, todas as equipes foram unânimes em qualificar a avaliação do projeto como aspecto contínuo que deve ser reforçado nas reuniões e nos processos formativos dentro da escola. Essas reuniões devem dinamizar e considerar os processos de ensino e de aprendizagem, utilizando as tecnologias digitais e móveis dentro da escola.

\section{Considerações finais}

Diante dos pressupostos elencados pelo Curso "Gestão das Tecnologias da Informação e Comunicação na Escola" e dos depoimentos dos gestores a partir da aplicação do questionário, percebemos que a estrutura adotada atingiu os objetivos inicialmente traçados.

No entanto, ainda é necessário reforçar a reflexão, sistematização e planejamento das formações continuadas, a fim de prestar melhor suporte ao gestor, visto que não dá para planejar a formação com um único modelo e estratégia para todos, precisamos compreender caso a caso. Na sondagem constata esta fala que o perfil tecnológico dos gestores que participaram deste curso é bastante heterogêneo e isso precisa ser levado em consideração nas formações continuadas.

Assim, compreendemos também que esses encontros ensejam discussões que estimulam e motivam o gestor a se envolver através da aprendizagem individual e coletiva, bem como entender os processos pelos quais estão passando, desenvolvendo estratégias que permitem ao grupo ultrapassar as barreiras e ampliar o conhecimento. Ademais, permitem compartilhar as dificuldades, medos, angústias e dúvidas, apoiando e recebendo apoio, sugestões e críticas no grupo. 
A partir disso podemos aferir, com base nos depoimentos dos gestores, que é necessário investir, cada vez mais na formação continuada, para que todos tenham sucesso, considerando as fragilidades e a deficiência da apropriação tecnológica de cada um, respeitando o ritmo de aprendizagem que é única e intransferível.

\section{Referências}

Almeida, M. E. B. e Prado, M. E. B. B. (2009). Formação de educadores para o uso dos computadores portáteis: indicadores de mudança na prática e no currículo.

Almeida, E. B.; Valente, J. A. (2011) Tecnologias e currículo: trajetórias convergentes ou divergentes? São Paulo: PAULUS. (Coleção questões fundamentais da educação).

Alonso, M. e Almeida, M. (2004). Biblioteca do curso Gestão Escolar e Tecnologias. Inserção de tecnologias na escola e formação continuada e em serviço de gestores, PUC-SP.

Brasil, Ministério da Educação (2009). Secretaria de Educação a Distância. UCA: Projeto Um Computador por Aluno. Brasília.

Bagatini, M. F; Almeida, M. E. B; Prado, M. E. B. B (orgs.) (2011). O computador Portátil na escola: mudanças e desafios nos processos de ensino e aprendizagem. São Paulo: Avercamp.

Fazenda, I. C. A. (1994). Interdisciplinaridade: história, teoria e pesquisa. Campinas: Papirus.

Fundação Victor Civita (FVC). (2010). Perfil dos diretores escolares. Estudos e Pesquisas Educacionais. v. 1. Editora: FVC, São Paulo.

Gil, A. C. (2002) Como elaborar projetos de pesquisa. 4. ed. São Paulo: Atlas.

Moran, J. M. Tablets e netbooks na educação. (2012) Disponível em: $<$ http://www.eca.usp.br/prof/moran/index7.html> Acesso em: 11/out/ 2013.

Nascimento, K. A. S. et al. Projeto UCA no Estado do Ceará: Caminhos Percorridos, Lições Aprendidas. In: XXII Simpósio Brasileiro de Informática na Educação e XVII Wokshop de Informática na Escola. Aracaju, 2011. Disponível em $<$ http://www.brie.org/pub/index.php/wie/article/view/1961>. Acesso em 29/09/2013.

Prado, M. E.; Borges, M. A.; França, G. (2011) O uso do laptop na escola: algumas implicações na gestão e na prática pedagógica. In: ALMEIDA, M. E. ; PRADO, M. E. (Orgs.) O computador portátil na escola: mudanças e desafios nos processos de ensino e aprendizagem. São Paulo: Avercamp, p. 60-72.

Vidal, H. M.; Maia, J. E; Santos, G. L. (2002) Educação, Informática e Professores. Fortaleza: Demócrito Rocha. 